\title{
La cohesión gramatical del español de los mi- grantes ancashimos bilingües de la asociación Carolina del distrito de Carabayllo
}

\author{
César Silvestre Herrrera \\ cesar830210@hotmail.com
}

\section{Resumen}

En este artículo se describe el empleo del mecanismo de cohesión gramatical de los migrantes ancashinos de la Asociación Carolina del distrito de Carabayllo. En rigor, se analizan los mecanismos cohesivos usados por hablantes bilingües quechua-castellano. El estudio se sustenta en la teoría lingüística del texto de van Dijk; además, el abordaje de los recursos de cohesión textual se realiza bajo los presupuestos de la teoría morfosintáctica y las asunciones del enfoque sociolingüístico, a fin de reconocer la forma en que el contacto de lenguas y la interacción lingüístico-social determinan patrones de vinculación textual diferentes del denominado castellano estándar.

Palabras clave: Cohesión gramatical, morfosintaxis, variación lingüística y bilingüismo.

\begin{abstract}
This article describes the use of the grammatical cohesion mechanism of ancashinos migrants who constitute a population of students and residents of the $\mathrm{Ca}-$ rolina Association of the Carabayllo District. The study is based on the linguistic theory of the text of Van Dijk, morphosyntactic theory and sociolinguistic in order to analyse the cohesion employed by the bilingual Spanish Quechua. Likewise, a comparison is made with the corresponding grammatical cohesion of the standard dialect.
\end{abstract}

Key words: Grammatical cohesion, morphosyntax, linguistic and bilingualism. 


\section{La cohesión giramatical del español de los migrantes ancashimos bilingïes de la asociación Carolima del distrito de Carabayllo}

\section{Introducción}

Las lenguas son sistemas o códigos cuyo nivel de abstracción debe entenderse en términos metodológicos. De esta manera, se conciben como estructuras con base en regularidades de naturaleza gramatical; sin embargo, tales regularidades se explicitan a través de un escenario diverso que está mediado por factores internos y externos; es decir, la dinámica de las lenguas se materializa a través de variedades o dialectos. En situaciones de coexistencia de varias lenguas en un territorio determinado, se presenta la situación de contacto lingüístico; tal es el caso del Perú, un país plurilingüe y pluricultural. Por eso, se requiere una investigación de los diversos componentes de la gramática a fin de describir o caracterizar tanto la oralidad como la escritura de los hablantes bilingües quechua-castellano. Los aportes iniciales de la situación de contacto entre el quechua y el castellano, realizados por Anna María Escobar (2000), consisten en la determinación de los diversos procesos morfosintácticos en el habla de los bilingües quechua-castellano. En tal sentido, entre otros aspectos, describe la estructura del orden de los constituyentes en las frases y las oraciones. En lo que concierne a la concordancia nominal, se describen las reduplicaciones pronominales, el doble condicional de los verbos en futuro indicativo, etc.

La presente propuesta considera que es posible estudiar la cohesión gramatical, tanto en un grupo de estudiantes como en la población bilingüe quechua-castellano que conforman la Asociación Carolina del distrito de Carabayllo. Este estudio reconoce que los estudiantes y los pobladores manifiestan diversos niveles de empleo de la cohesión gramatical en las modalidades oral y escrita de la lengua española, y busca determinar los mecanismos empleados por los estudiantes en el uso de la cohesión gramatical.

Para lograr el propósito principal de la descripción ha sido necesario realizar el análisis de cómo se manifiesta la cohesión gramatical en bilin- 
gües, pues de esta forma se procuró establecer explicaciones consistentes con el comportamiento de esta. Las implicancias aplicativas de la investigación consisten en la implementación de técnicas adecuadas y la aplicación pertinente de herramientas de enseñanza-aprendizaje acordes con el escenario diverso y las necesidades que se derivan de este en centros educativos en los que se imparte la educación intercultural, pues es importante favorecer un óptimo empleo de los recursos lingüísticos y discursivos esenciales para expresar los contenidos en organizaciones textuales narrativas, descriptivas. La propuesta, asimismo, permite incrementar el léxico y determinar el procesamiento de contenidos con el ejercicio de habilidades en la escritura.

En lo concerniente a la cohesión gramatical de los bilingües ancashinos, la recopilación de datos se realizó a través de las siguientes técnicas e instrumentos de investigación:

- Redacción de textos narrativos en los cuales se usaron los mecanismos de cohesión y coherencia, con la consideración de las normas prescriptivas del idioma, el empleo adecuado de los conectores, la concordancia y otros aspectos importantes.

- Fichas de preguntas para completar los mecanismos de cohesión gramatical.

El objetivo del estudio es determinar los mecanismos de cohesión usados por los migrantes ancashinos de la Asociación Carolina (distrito de Carabayllo) desde la perspectiva textual y el enfoque sociolingüístico, pues correlaciona los aspectos lingüísticos-textuales y los correlaciona con variables sociales. De esta forma, da cuenta la forma en que los hablantes muestran varios niveles de empleo de la cohesión gramatical en sus construcciones textuales. Las implicancias comparativas de la pesquisa se explicitan en los engarces necesarios del dialecto castellano de los bilingües ancashinos con el denominado castellano estándar, a fin de definir las orientaciones del cambio producido por el contacto lingüístico quechua-castellano.

\section{Aspectos teóricos}

Con la finalidad de definir no solo las particularidades lingüísticas de los textos articulados por hablantes bilingües, sino de definir cuáles son las relaciones con el fenómeno del contacto lingüístico, se precisa de los presupuestos de la lingüística textual, la morfosintaxis y la sociolingüística. Estas teorías se desarrollarán de forma razonada en los siguientes párrafos. 


\subsection{Lingüística textual}

Enrique Bernárdez (1985, p. 154) define la lingüística del texto como el estudio de la comunicación humana, como fenómeno global explicitado mediante el lenguaje; es decir, la lingüística textual aborda el proceso en su integridad, sin limitarse a uno de sus factores. Es por ello que podemos confirmar que el punto de partida fundamental de la lingüística del texto es el conjunto del proceso comunicativo mediante el lenguaje.

Al analizar el proceso comunicativo en su conjunto, la lingüística del texto se aproxima a otras disciplinas centrales en fenómenos tradicionalmente olvidados por la "lingüística propiamente dicha" (1985, p. 155g). Dicho en otros términos, el análisis holístico que se desprende del análisis textual debe entenderse a través de la consideración de que, desde el punto de vista humano, la comunicación es una forma de actividad, lo que es una característica corriente de muchas tendencias de la lingüística textual, de manera que se aborda el lenguaje en uso con lo cual se extiende un vínculo idiosincrático con los enfoques pragmáticos. La construcción de textos es un proceso y un producto del lenguaje, y por ello debe evaluarse en su real dimensión de acuerdo con los elementos lingüísticos y extralingüísticos que lo caracterizan.

La teoría textual, en suma, permitió elaborar una caracterización razonada de los procesos comunicativos del bilingüe quechua-español, direccionados por la macroestructura textual; es decir, tanto los textos orales como los escritos se configuran comunicativamente, lo cual revela que estos productos están influenciados fuertemente por factores extralingüísticos.

\subsubsection{La hipótesis “macroestructural” de van Dijk (1972)}

Para van Dijk, las relaciones interfrásticas están relacionadas con aspectos muy importantes de la configuración textual: la anáfora, los pronombres, la presuposición, la implicación, etc. En este sentido propone como base teórica el soporte gramatical detectable en enfoques formalistas como el de Chomsky, pero tomando como estructura fundamental de análisis el esquema textual y no la sintaxis; es decir, se parte de la noción de texto como unidad de análisis con lo cual se supera el nivel oracional.

También supone que todo hablante (que se vincula también con la noción de lector) posee una competencia y una actuación de naturaleza textual que le permiten analizar cualquier secuencia de unidades textuales y al mismo tiempo organizar varios tipos de interrelaciones entre ellas en varios planos semánticos y con variadas funciones. No se trata de comprender y producir series de oraciones, sino de estructurar unidades textuales en un sistema de relaciones internas y externas. Por esta razón, propone el estudio de lo que él llama "macroes- 
tructuras" (estructuras globales de textos completos) que organizan las series o secuencias de unidades que configuran el texto.

\subsection{Morfosintaxis}

\subsubsection{La estructura morfosintáctica de la gramática generativa}

Considerando la teoría estándar de la teoría generativa de Noam Chomsky (1965), la gramática está constituida por tres componentes: sintáctico, semántico y fonológico. El primero contiene las reglas de rescritura, las reglas de subcategorización y las reglas de inserción léxica a fin de obtener la estructura profunda, la cual se relaciona con la estructura superficial mediante el componente transformacional. Los componentes semántico y fonológico cuentan con reglas de interpretación.

Para comprender la estructura de las oraciones, es importante tomar en cuenta las relaciones de coocurrencia explicitadas por Koutsoudas (1966, pp. 95-96), quien las precisa de la siguiente manera:

Respecto de la estructura sintáctica de las oraciones, es conveniente considerar las relaciones de coocurrencia. Este autor refiere que existe un número de relaciones gramaticales que pueden ser definidas y agrupadas en tres tipos básicos. Los ejemplos dados se corresponden con el inglés, pero, para propósitos de este estudio, se proponen ejemplos del español.

El primer tipo de relación de coocurrencia es una de dependencia simple (o unidireccional) entre dos o más clases. Específicamente, en una posición bien especificable dentro de un conjunto de oraciones, la ocurrencia de una clase requiere la ocurrencia de la otra u otras, pero no viceversa. Por ejemplo, la ocurrencia de una frase preposicional o un adverbio en el predicado requiere la presencia del verbo intransitivo (Julio viajará en tren; Julio viajará mañana), pero la ocurrencia de un verbo intransitivo no requiere la presencia de un adverbio o una frase preposicional, pues estos son opcionales; tal es el caso de la oración Julio viajará.

El segundo tipo de relación de coocurrencia es una de dependencia mutua (o bidireccional) entre dos o más clases. Específicamente, en una posición bien especificable dentro de un conjunto de oraciones, una clase ocurre siempre con la otra u otras y viceversa. Por ejemplo, en una oración compuesta por subordinación sustantiva finita afirmativa de estilo indirecto, el verbo transitivo requiere de una cláusula subordinada que contenga la conjunción subordinante que; y esta requiere que haya un verbo transitivo (María informó que obtuviste un premio). De esta forma, son agramaticales las oraciones del tipo *María informó obtuviste un premio o *María que obtuviste un premio. 
El tercer tipo de relación de coocurrencia es una relación de dependenciamutuamente exclusiva entre (a) dos o más clases o (b) unos miembros de una clase con ciertos miembros de otra clase. Un ejemplo de (a) es que el pronombre y el nombre no coocurren en posición de sujeto: tal es el caso de la agramaticalidad en la oración *Él Mario canta bien. Un ejemplo de (b) es que ciertos nombres no pueden ser objetos de ciertos verbos: *Juan camina un poema o *Juan corre un libro.

Esta teoría es menester para determinar la consistencia de la concordancia nominal en castellano y la forma en que esta se explicita en construcciones textuales de los bilingües ancashinos quechua-español, pues de esta manera será posible describir y explicar los fenómenos ocurrentes debido al contacto lingüístico. Además, será posible definir cuáles son las diferencias respecto del dialecto estándar.

\subsection{Sociolingüística}

Aikhenvald (2007, p. 47) afirma que "Las lenguas reflejan la historia sociolingüística de sus hablantes; y las actitudes lingüísticas influencian el resultado del contacto". La situación sociolingüística de los bilingües ancashinos está caracterizada por la imposición del castellano, y tensión evidenciada en la preservación de la lengua y la cultura quechua, o el rechazo de estas. A pesar de los importantes cambios en la política lingüística del país en las últimas décadas -entre otras la proclamación del quechua como lengua oficial y la introducción de un programa intercultural bilingüe- el quechua se percibe como una lengua inferior al castellano, no solo por los hablantes monolingües castellano, sino por los propios hablantes de quechua. La falta de transmisión del quechua es explicable si se analiza la historia de sus hablantes. Recordemos que, en el marco del enfoque sociolingüístico, "La lengua es un fenómeno histórico surgido en el desarrollo de la especie humana por el efecto combinado de procesos de pensamiento, habilidades perceptivo-motoras, capacidades cognoscitivas y factores sociopragmáticos, que operan recíprocamente" (Moreno Fernández, 2012, p. 24). En atención a lo propuesto por Moreno, la búsqueda de respuestas sobre los fenómenos lingüísticos debe sustentarse empíricamente, pues involucra la actuación real signada por la coocurrencia de factores extralingüísticos. Así, años de abusos y exclusión de ciertas poblaciones por su condición de "quechuahablante" ha marcado psicológicamente tanto a padres de familia como a maestros, quienes actualmente procuran evitar que los niños sufran la misma discriminación de la cual ellos fueron víctimas; en el peor de los casos, es posible que también se hayan convencido de una supuesta inferioridad del quechua respecto al castellano, de manera que las actitudes frente a su propia lengua son negativas. Las actitudes lingüísticas de los hablantes influyen considerablemente en la vitalidad del quechua y en el resultado del contacto lin- 
güístico quechua-castellano, y son fenómenos cuyo abordaje amerita una óptica sociolingüística.

En nuestra investigación se considera la edad, la educación y el tiempo de permanencia de los bilingües ancashinos de la Asociación Carolina del distrito de Carabayllo, a fin de describir el nivel de cohesión de los hablantes.

\subsection{La cohesión gramatical}

Un texto es coherente si su estructura significativa presenta organización lógica, armonía sintáctica, relación semántica y pragmática entre sus partes. El texto es congruente cuando los elementos que lo forman mantienen una relación de conexión. Al respecto, García B. y Petöfi (1978) plantean que la coherencia o la congruencia de un texto es una propiedad de la sustancia textual, que a nivel de la forma textual se traduce en el conjunto de mecanismos lingüísticos de cohesión.

En ese sentido, para que un texto resulte coherente entre sus componentes, deben intervenir los elementos de la cohesión gramatical a través de dos niveles: el referencial y el conectivo.

En cuanto al nivel referencial, se muestran elementos implícitos o explícitos en la lectura y la escritura. Por ello, es preciso señalar que el empleo adecuado permite al hablante expresar un mensaje coherente y armónico para producir y persuadir al interlocutor; de la misma manera, es útil para comprender las diferentes tipologías de textos, ya sean informativos o de otra naturaleza (tanto escritos como orales).

Las definiciones de los conectivos muchas veces son vagas porque no son excluyentes. Esto ocurre, por ejemplo, en casos como el conector de contraste, aunque, el cual se emplea como conector concesivo. También es posible que ciertas secuencias conectivas modifiquen su espectro semántico en el discurso concreto: es lo que ocurre con la secuencia como+que, la cual puede determinar que el espectro de lo fáctico se relativice (Rocha M. y Conde M., 2013), aun cuando su función medular es la de referirse a lo probable; es decir, la secuencia en cuestión define que hechos corroborables sean asumidos como eventos posibles. A la vista de estos casos, es necesario que el investigador se comprometa al rastreo de cada una de las partículas involucradas en la producción y la comprensión de textos coherentes y cohesionados. Por otro parte, para Halliday y Hasan (1976, p. 17), "la cohesión consiste en el conjunto de todas aquellas funciones lingüísticas que indican relaciones entre los elementos de un texto". En concordancia con lo señalado, los marcadores son unidades lingüísticas que permiten cohesionar - o dar unidad a- un texto.

Sin embargo, desde el punto de vista que adoptamos, que se aproxima a alguno de los nuevos planteamientos de la lingüística textual más influido por 
la pragmática, la cohesión discursiva no es un fin en lo que concierne a la utilización de marcadores, sino un producto. Percibir estas unidades únicamente como marcas de cohesión no explicaría, por ejemplo, cuál es el motivo de su acumulación en algunos discursos. A fin de analizar las implicancias de la cohesión mediante conectores, planteamos el siguiente caso:

(1) Hay temporal y, en consecuencia, la flota no saldrá a faenar.

¿Por qué utilizamos en consecuencia si ya tenemos la conjunción y para cohesionar? La respuesta es la siguiente: cuando interactuamos discursivamente, intentamos comunicar de forma pertinente, o tal vez enfatizar algún aspecto del marco informativo que estructuramos; para ello, en ocasiones, se precisa de la ocurrencia de diversos marcadores del discurso a fin de explicitar el texto de forma más clara.

\subsection{La referencia}

Halliday y Hasan (1976, p. 18) plantean lo siguiente: "El mecanismo de cohesión establece una relación entre un elemento del texto y otro que están presentes en el mismo texto o en el contexto situacional". Lo anterior supone no solo un componente relacional entre unidades del texto, sino entre los contenidos de este, de acuerdo con la lectura del contexto que se construye de forma compleja en la interacción verbal. En palabras de los autores, el entramado textual define referentes que son identificables, de manera que la reconfiguración de los aspectos relevantes del texto y la comprensión cabal de estos depende del marco referencial. A propósito de esto, Halliday y Hasan proponen dos tipos de referencia en el texto: la de tipo exofórica y la de carácter endofórica.

Las referencias son marcadores que permiten cohesionar un texto escrito $\mathrm{u}$ oral; por ello presentan una relevancia alta en los hablantes. El uso de estas se justifica en el marco de un compromiso por evitar un discurso monótono y articular más bien uno de carácter dinámico y fluido. Básicamente, la referencia presenta remitiendo a un concepto ya mencionado o por mencionar. A continuación, se propone un ejemplo adicional a fin de graficar el espectro relacional.

(2) Luis visitó a su hermana, pues pensó que ella estaba enferma.

En (2), se constata que la palabra ella constituye una referencia al concepto expresado por la estructura nominal su hermana (y no como sustitución directa del lexema hermana, pues no tendría sentido decir "pensó que hermana estaba enferma); es decir, a un elemento del discurso mismo. A nivel textual, planteamos la siguiente estructura: 
(3) "Y esto — dijo el señor Dieudonne Duval moviendo el bigote- es de una ingeniosidad incomparable, amigo mío, tal vez no sea yo el más indicado para decirlo, pero si lo mira bien ino te parecen como dicen ustedes algo fantástico?”. [El resaltado es nuestro]

La palabra esto hace referencia a un objeto, un ser o una situación que pertenece al campo de la experiencia inmediata de los interlocutores, funciona entonces de manera equivalente a como lo haría un nombre o sintagma nominal específico que nombrara a ese objeto, ese ser o esa situación. La referencia ya no es interna (elemento del texto), sino que se proyecta hacia fuera de él; a saber, hacia el mundo de la realidad externa.

\section{a. Referencia exofórica}

Halliday y Hasan (1976, p. 18) afirman que esta referencia se presenta en casos en los que un elemento textual hace referencia a elementos diversos de la realidad o se engarza con factores de tipo extralingüístico (es decir, aquellos que no están en el texto), los cuales se entienden que se vinculan o están asociados con el contexto situacional. A continuación, proponemos el siguiente ejemplo:

(4) Nosotros somos parte esencial de la Universidad de San Marcos.

En el caso presentado en (4), el pronominal Nosotros establece una relación con alguno de los estamentos que hace parte de la Universidad de San Marcos y que no está presente en el texto: estudiantes, profesores, empleados, trabajadores, entre otros.

Esta referencia alude al elemento que no está presente en el texto explicitado oralmente, lo que exige un compromiso del interlocutor al desencadenamiento de mecanismos interferenciales para comprender cabalmente el mensaje emitido en la comunicación lingüística (ya sea oral o escrita). En situaciones como esta, muchas veces, el destinatario no escatima en recursos o mecanismos que hagan posible el desciframiento del mensaje.

\section{b) Referencia endofórica}

Halliday y Hasan (1976, p. 284) precisan que la referencia de esta clase se presenta en los casos en los cuales la relación se establece con un referente textual interno; es decir, el vínculo se corresponde con referencias presentes en el mismo texto, como se propone en (5):

(5) Nos hizo una oferta excelente. En ella, describe con precisión todas las ventajas de la alianza. 
El pronombre personal ella hace referencia a un grupo nominal que está presente en el mismo texto: una oferta excelente. Respecto de las referencias endofóricas, estas se clasifican en anafóricas y catafóricas.

Los presupuestos teóricos básicos propuestos definirán un tipo de análisis del texto, no solo vinculado con aspectos formales sustentados en abstracciones, sino en elementos extratextuales de naturaleza discursiva, los cuales suponen la consideración de eventos discursivos reales.

\section{Metodología de investigación}

\subsection{Población y muestra}

La población que ha conformado el universo de estudio ha estado conformada por hablantes bilingües quechua-castellano. En cuanto a la variable etaria, estos oscilaban entre individuos de 6 años hasta personas de 60 años. A continuación, presentamos el número total de colaboradores, distribuidos según la variable edad (tabla 1). A fin de que la muestra se corresponda con un número simétrico de hablantes bilingües, se precisó de diez individuos por cada grupo etario. Los grupos etarios definidos fueron cuatro.

Tabla 1. Total de participantes por grupo etario

\begin{tabular}{|c|c|}
\hline Edades & $\mathbf{N}^{\circ} \mathbf{o}^{\text {de }}$ participantes \\
\hline 6-12 años & 10 \\
\hline $12-18 / 19$ años & 10 \\
\hline $20-25$ años & 10 \\
\hline 26-60 años & 10 \\
\hline Total & $\mathbf{4 0}$ \\
\hline
\end{tabular}

Del total de participantes, 20 son alumnos del CEBA “Miguel Ángel”. La población del presente estudio de investigación comprende a los estudiantes y a los pobladores migrantes ancashinos de la Asociación Carolina del distrito de Carabayllo. El número total de colaboradores fueron 40.

\subsection{Técnicas e instrumentos de recolección de datos}

En cuanto al empleo de los instrumentos de recolección, se consideraron dos herramientas fundamentales: una prueba de reconocimiento y un ejercicio de redacción. Estas se describen a continuación. 
- Prueba sobre los mecanismos de cohesión gramatical a los migrantes ancashinos del distrito de Carabayllo.

- Redacción de textos narrativos, expositivos, en los cuales se analizó el empleo de los mecanismos de cohesión gramatical de los migrantes ancashinos del distrito de Carabayllo.

Después del análisis de la realidad empírica relativa a mecanismos de cohesión en los textos articulados oralmente y de manera escrita, tanto de los migrantes ancashinos en el colegio no escolarizado CEBA "Miguel Ángel” como de los pobladores del distrito de Carabayllo, se realizó una descripción de las principales herramientas de cohesión gramatical de los migrantes ancashinos.

\section{Análisis de los datos}

El ámbito de los recursos gramaticales en la constitución de textos ha sido el menos explorado desde el punto de vista del castellano con interferencias del quechua. Este déficit será un punto inicial de análisis de los fenómenos en los que el quechua convive con el español, específicamente aquellos en los que la estructuración de textos suponga la conformación de patrones bastante definidos de cohesión. Este es el objetivo fundamental del presente capítulo, el cual está orientado, en rigor, a la descripción y la explicación de la cohesión gramatical de los bilingües ancashinos de la Asociación Carolina del distrito de Carabayllo. El contacto lingüístico en esta comunidad de habla permite que los lugareños usen una serie de recursos lingüísticos que sirven para optimizar la comunicación. Por ello, ha sido posible la identificación de recursos cohesivos y los tipos de referencias gramaticales, tanto de tipo cuantitativo como cualitativo, mediante el análisis de textos. En (6), presentaremos el caso de un texto elaborado por una de los informantes. Este servirá como muestra general, ya que, más adelante, se presentarán datos de otro de los informantes en cuestión.

(6) Redacción de texto

\section{Lesly Murga}

Narra un cuento

Había una vez, una mujer que era muy pobre que vivía solo en una casa y pasaba su vida en ayudando a sus vecinas de quehaceres en cosas como y pasteando sus animales así vivía durante todo tiempo a su vecinos no tuvo su hijo por más que quería tener su hijo y estuvo muy triste durante toda su vida, a pesar de que pasaron los años ella tenía más edad. En eso uno de los día muy triste se fue a descansar a su cama en eso, tuvo un sueño profundo y entre sus sueños tuvo su hijito y se despertó muy pensativo y a la vez muy feliz que iba tener un hijo y por primera vez iba ser madre y pasos meses y como que tuvo sueño de tener hijo se hizo la 
realidad y cuando tuvo nueve meses dio luz. Su bebe nació de serpiente entonces la mujer cuando lo vio a su bebe que era serpiente. Desconsolante lloró y tampoco no podía creer que su bebe era serpiente entonces la madre este niño serpiente lo hecho en baúl y lo guardó en un lugar muy seguro donde nadie podía verlo o encontrarlo y entre sus sueños el niño serpiente le revelaba su madre que nunca deje de querer por que más que sea un serpiente y siempre que le cuide y pasaba revelando en sus sueños y uno de esos sueños cuando pasaron los años lo dice mamá quiero una novia y casarme y tener una familia entonces su madre muy preocupada ya avergonzado de enfrentar la situación de lo que anhela tener su hijo. Pero cuando salió a buscar novia y decía que su hijo nació serpiente y nadie en el pueblo captaron para asacase con su hijo. Y cuando está en el camino casi por llegar por acá se encuentran con una chicha deforme y sordomuda y pastora de porcinos, y ella de tanta suplica de la madre la acepto casarse con su hijo serpiente. Y entonces seguí revelando entre su sueño le pregunta a su madre que si encontró la novia o no y ella le responde que sí. Entonces planea que esa se semana se va a casarse. Que preparen y manden invitación a toda sus familiares. Entonces llegó ese día tan esperado de cumplir su deseo sus madre lo lleva en ese baúl que siempre ha estado durante su vida soltera. Y la novia estaba en el altar esperando que se lleva a cabo la boda y allí estaban todos los invitados rodeados. Su madre lo pone en el altar dentro del baúl a lado de la novia y había un sacerdote se lleva acabo y ente eso le dice el juramento de amor y la novia estaba indecisa y entre eso salió el novio salió bien elegante convertido de serpiente a una persona.

\subsection{Cohesión gramatical usados por hablantes bilingües ancashinos de la Asociación Carolina}

Después de la aplicación de la fichas a los colaboradores y la composición de los textos (escritos y orales) por parte de estos, efectuó el análisis de tipo comparativo para determinar las diferencias apremiantes entre los mecanismos de cohesión textual en hablantes bilingües y los que se corresponden con el castellano estándar como abstracción. Algunos de los ejemplos de expresiones de los bilingües son los siguientes:

(7) a. Las plantas nos dan oxígeno. Así que, cuídalos.

b. La abeja está en su colina. Ellos nos proporcionan miel.

En la primera oración se presenta la discordancia entre el referente anafórico y el antecedente nominal con el cual se relaciona, específicamente en lo concerniente al género. En lo que concierne al segundo caso (7b), la asimetría gramatical se constata en el género y el número. Estas son muestras bastante específicas de la forma en que se reconfiguran los mecanismos cohesivos en la 
estructuración de textos en hablantes bilingües ancashinos, aunque bien podría extenderse a cualquier quechuahablante bilingüe. Si bien es cierto, existen asimetrías, estas podrían ser explicables de acuerdo con el desplazamiento de las formas endofóricas por la exofóricas. Es decir, mientras que, en el primer caso, el uso de los podría estar mediado por la vinculación de un referente neutro respecto del género, en lo que concierne al uso de ellos (que supondría en la forma estándar la ocurrencia de ella) estaría involucrado por la consideración semántica del conjunto vinculado con el enjambre.

Por otro lado, las asimetrías más frecuentes ocurren en las siguientes formas de uso: el empleo de sustitución léxica que consiste en utilizar sinónimos o nexos para vincular los enunciados. En los datos presentados en (8), servirá de muestra para establecer con mayor claridad las correspondencias heteróclitas de los mecanismos de cohesión textual.

(8) a. Pero cuando salió a buscar novia.

b. Su madre lo pone en el altar dentro del baúl.

c. Anhela tener su hijo.

d. Sea un serpiente y siempre que le cuide.

A lo largo de texto narrativo predominan las palabras madre, hijo, novia y serpiente. En el dialecto de los bilingües, existe una ausencia de sustitución; por lo tanto, predomina la redundancia (o reiteración de referentes nominales) al momento de escribir y hablar. Así, durante la exposición de un texto narrativo y en la redacción de un cuento, las reiteraciones de nombres ya explicitados son frecuentes. Vale decir, ellos emplean el mismo vocablo a lo largo de la construcción sintáctico-textual. ¿Por qué se produce esto? Si bien es cierto, podría resultar razonable que su correncia está asociada con el nivel de formación de los informantes, son las transferencias interlingüísticas en un proceso de adquisición las que constituyen el origen de estos casos.

Asimismo, en el empleo de referencias denominadas anáforas, catáforas y elipsis, que anuncian elementos o conceptos que se han explicitado antes o aparecerán después, predomina la discordancia y la ausencia de muchos pronombres gramaticales átonos, así como el empleo de los marcadores textuales o conectores lógicos; por lo general, se utilizan los aditivos y los causativos en lugar de los demás. Un ejemplo de este tipo es el siguiente:

(9) Visitó a sus parientes, pero no lo apoyó.

En la oración anterior se manifiesta una asimetría en el uso del referente anafórico. Esto es, el número gramatical del pronombre átono es lo aun cuando debería ser los. La ocurrencia de esta forma podría deberse nuevamente a la conexión con un referente exofórico. Es decir, se torna consistente la vinculación fuera del texto y no dentro de él. A nivel formal basta la conexión con el 
conector adversativo pero; sin embargo, el elemento pronominal puede establecer equivalencias con referentes fuera de toda la estructura proposicional o enunciativa.

Si bien es cierto, la recopilación de datos se efectuó mediante la composición de textos por parte de los informantes. El uso de recursos anafóricos también se evaluó a través de un instrumento en el cual el informante podía escoger el pronominal más adecuado en contextos específicos. Este recurso en particular será desarrollado en los párrafos siguientes.

\section{Informante C1}

\section{Los resultados de las referencias gramaticales de los migrantes ancas- hinos de 6 a 12 años de edad.}

Complete con los pronombres personales átonos adecuados (la/s, lo/s le/s)

(10) a. Visitó a sus parientes, pero no los apoyó.

b. El diploma lo colgué en la pared de mi cuarto.

c. Les dijo a sus amigos que sean más cautos.

d. El mapa y la lámina les devolvió.

e. La vi muy asustada a Raquel.

f. Leyó esas obras, mas no la interpretó.

g. La amplia área lo pintaron ayer.

h. Lo vi bastante cansado a Jorge.

i. Le pedí un consejo a Javier.

Los bilingües ancashinos presenta aspectos peculiares de asimetrías de género y número frente al dialecto estándar del castellano. Por ejemplo, la amplia área lo pintó ayer, Leyó esas obras, mas no la interpretó y El diploma le colgué en la pared de mi cuarto. En cada uno de los casos los pronominales son divergentes de los referentes articulados previamente.

\section{Informante C2}

\section{Los resultados de las referencias gramaticales de los migrantes ancas- hinos de 12 a 18 / 19 años de edad.}

Complete con los pronombres personales átonos adecuados (la/s, lo/s le/s)

(11) a. Visitó a sus parientes, pero no los apoyó.

b. El diploma lo colgué en la pared de mi cuarto.

c. Los dijo a sus amigos que sean más cautos.

d. El mapa y la lámina las devolvió.

e. Le vi muy asustada a Raquel. 
f. Leyó esas obras, mas no lo interpretó.

g. La amplia área lo pintaron ayer.

h. Lo vi bastante cansado a Jorge.

i. Le pedí un consejo a Javier.

En esta prueba de aplicación se percibe los siguientes casos: "Los dijo a sus amigos que sean más cautos." El uso del pronombre "los" como elemento catafórico del sustantivo "amigos" El mapa y la lámina las devolvió." "Las" como referencia anafórica de las frases "El mapa y la lámina". "Le vi muy asustada a Raquel." "Le” como referencia catafórica del sustantivo Raquel. Y, por último, "La amplia área 'lo' pintaron ayer". "Lo" es referencia de la amplia aula área.

\section{Informante C3}

Los resultados de las referencias gramaticales de los migrantes ancashinos de 20 a 25 años de edad.

Complete con los pronombres personales átonos adecuados (la/s, lo/s le/s)

(11) a. Visitó a sus parientes, pero no lo apoyó.

b. El diploma lo colgué en la pared de mi cuarto.

c. Lo dijo a sus amigos que sean más cautos.

d. El mapa y la lámina lo devolvió.

e. La vi muy asustada a Raquel.

f. Leyó esas obras, mas no las interpretó.

g. La amplia área lo pintaron ayer.

h. Lo vi bastante cansado a Jorge.

i. La pedí un consejo a Javier.

En esta prueba de aplicación se registran casos el siguiente: Visitó a sus parientes, pero no lo apoyó. En este, el uso del pronombre lo es el elemento anafórico del sustantivo parientes; sin embargo, difiere de la relación gramatical de número. Por otro lado, en el caso (11d) El mapa y la lámina lo devolvió, la relación se mantiene en singular, aun cuando debería manifestarse una correspondencia en plural mediante el pronominal los, aunque en hablantes monolingües es posible detectar el uso de la debido a la relación directa con el último elemento nominal de la frase (la lámina).

\section{Informante $\mathrm{C} 4$}

Los resultados de las referencias gramaticales de los migrantes ancashinos de los 26 / 60 años de edad. 
Complete con los pronombres personales átonos adecuados (la/s, lo/s le/s)

(12) a. Visitó a sus parientes, pero no lo apoyó.

b. El diploma la colgué en la pared de mi cuarto.

c. Le dijo a sus amigos que sean más cautos.

d. El mapa y la lámina lo devolvió.

e. Lo vi muy asustada a Raquel.

f. Leyó esas obras, mas no la interpretó.

g. La amplia área la pintaron ayer.

h. Le vi bastante cansado a Jorge.

i. Lo pedí un consejo a Javier.

En la prueba anterior, relativa al informante $\mathrm{C} 4$, se registran casos como el de Visitó a sus parientes, pero no lo apoyó, en el cual se usa el pronombre lo como elemento anafórico del sustantivo parientes. También es posible detectar el uso de un pronominal en singular en correspondencia con una estructura en plural: Le dijo a sus amigos que sean más cautos. finalmente, la predominancia del masculino, en El mapa y la lámina lo devolvió, cuyo uso de lo como referencia anafórica de la estructura El mapa y la lámina es interpretado como la correspondencia con el género masculino debido a la ausencia del femenino como marca gramatical en quechua. Finalmente, casos en los que el dativo reemplaza al acusativo (le por lo) como Le vi bastante cansado a Jorge supone un reacomodo en el cual el pronombre de dativo Le constituye la referencia catafórica del sustantivo Jorge.

Ejemplos de textos

\section{Informante $\mathbf{C} 1$}

Empleo de conectores lógicos textuales:

Había una vez, una mujer que era muy pobre que vivía solo en una casa y pasaba su vida ayudando a sus vecinas de quehaceres en cosas como y pasteando sus animales así vivía durante todo tiempo a su vecinos no tuvo su hijo por más que quería tener su hijo y estuvo muy triste durante toda su vida, a pesar de que pasaron los años ella tenía más edad. En eso uno de los día muy triste se fue a descansar a su cama en eso, tuvo un sueño profundo y entre sus sueños tuvo su hijito y se despertó muy pensativo y a la vez muy feliz que iba tener un hijo y por primera vez iba ser madre y pasó meses y como que tuvo sueño de tener hijo se hizo la realidad y cuando tuvo nueve meses dio luz. Su bebe nació de serpiente entonces la mujer cuando lo vio a su bebe que era serpiente.

Existe un predominio de conectores lógico-textuales aditivos en la cohesión gramatical de los migrantes ancashinos y asimetrías en la concordancia de género y número como en los casos de (i) una mujer que vivía solo en la casa y (ii) 
su vecinos le ayudando. En este último se constata la concordancia en número y el empleo del pronombre átono le. Es posible la ausencia completa de especificación mediante el artículo definido. Tal es el caso de (iii) Así vivía durante todo Ø tiempo a su vecinos; en este el artículo el se suprime (del mismo tipo es la estructura enunciativa fue en $\varnothing$ sala de partos. La oración (iv) manden invitación a toda sus familiares presenta la forma toda, la cual parece concordar con invitación. La reiteración permanente de formas nominales como serpiente, aunque no es el único caso, involucran un mecanismo de recojo de datos previos necesario para la construcción textual.

La ausencia de subordinantes es un rasgo típico del dialecto castellano de bilingües quechua-castellano. La mayoría de las ideas están cohesionadas por el conector copulativo $y$, de manera que se generaliza en la comunicación oral y visuográfica. Este fenómeno ocurre por la ausencia de conectores lógicos textuales en la lengua.

\subsection{Comparación de la cohesión gramatical de los bilingües ancashinos con la cohesión gramatical de la variedad estándar}

A continuación, se propone un cuadro de comparación entre el mecanismo de cohesión de los migrantes ancashinos y el dialecto estándar del castellano (tabla 2).

Tabla 2. Cuadro comparativo de recursos de cohesión mediante conectores entre el castellano de bilingües y la variedad hispana estándar

\begin{tabular}{|l|l|l|}
\hline \multicolumn{1}{|c|}{$\begin{array}{c}\text { Conectores lógicos } \\
\text { textuales }\end{array}$} & \multicolumn{1}{c|}{$\begin{array}{c}\text { Bilingües } \\
\text { ancashinos }\end{array}$} & \multicolumn{1}{c|}{ Variedad estándar } \\
\hline Conector aditivo & $\mathrm{y}$ & $\mathrm{y}, \mathrm{e}$, ni, que \\
\hline Conector disyuntivo & $\mathrm{o}$ & $\mathrm{o}, \mathrm{u}$ \\
\hline Conector adversativo & Pero & $\begin{array}{l}\text { pero, sino, sin embargo, no obstante, } \\
\text { empero, mas }\end{array}$ \\
\hline Conector ilativo & Luego & $\begin{array}{l}\text { por ello, por eso, por lo tanto, luego, } \\
\text { entonces, conque, pues }\end{array}$ \\
\hline
\end{tabular}

A partir de este cuadro comparativo se llega a la conclusión de que los bilingües quechua-español ancashinos emplean en la mayoría de las construcciones gramaticales sin tomar en cuenta el contexto ni el significado que deviene de las relaciones entre proposiciones o unidades textuales y los conectores lógicos textuales $y$, o, pero y luego. Por otro lado, en la variedad estándar se busca evitar la cacofonía; por consiguiente, se precisa de la delimitación de antecedentes y consecuentes para emplear los diferentes tipos de elementos cohesivos.

En cuanto al uso de pronominales átonos, existen también divergencias entre el dialecto de hablantes bilingües y el dialecto estándar (ver tabla 3). 
Tabla 3. Diferencias en el uso de pronominales entre el castellano estándar y el castellano de bilingües ancashinos quechua-castellano

\begin{tabular}{|c|c|c|}
\hline Elementos de referencia & Bilingües ancashinos & Variedad estándar \\
\hline $\begin{array}{c}\text { Pronombres átonos que fun- } \\
\text { cionan como OD }\end{array}$ & le, lo, me & $\begin{array}{c}\text { la, las, lo, los, me, te, se, } \\
\text { nos }\end{array}$ \\
\hline $\begin{array}{c}\text { Pronombres átonos que fun- } \\
\text { cionan como OI }\end{array}$ & le, lo, me & le, les, me, te, se, nos \\
\hline Elipsis & $\varnothing$ & $\varnothing$ \\
\hline concordancia en género & le, lo & les, La, las, lo, los, \\
\hline Concordancia en número & le, lo & la, las, lo, los, me \\
\hline
\end{tabular}

En este cuadro comparativo, se plantean los pronombres átonos de tipo anafórico y catafórico de los bilingües quechua-castellano. En este se evidencia un menor espectro de usos anafóricos debido a la predominancia de pronominales en su forma singular. además, la frecuencia de uso de los pronombres le y lo en las estructuras textuales evidencian la asimetría de número y de género, la cual se decanta por la predominancia del singular masculino como elemento neutro en el castellano de bilingües, en contraposición con las formas pronominales de la variedad estándar del español, en la cual se distinguen las formas de género y de número.

La explicación plausible es que la ausencia de género gramatical en quechua, además de la ausencia de pronominales átonos para el acusativo y el dativo (con sus formas singulares y plurales), determina la ocurrencia predominante de los pronominales le y lo, los cuales neutralizan tales distinciones en castellano, a fin de orientar la interpretación de los referentes textuales en términos semántico-textuales más que gramaticales.

\section{Conclusiones}

Este trabajo de investigación permite describir y explicar los mecanismos de cohesión gramatical en las unidades textuales de los migrantes ancashinos bilingües quechua-castellano del distrito de Carabayllo. A la luz de la evidencia, se concluye lo siguiente:

1. El sistema de cohesión gramatical de los migrantes ancashinos de la Asociación Carolina del distrito de Carabayllo presenta características peculiares debido al carácter bilingüe de los hablantes, por lo que hay diferencias con respecto a la cohesión gramatical empleada por los hablantes que manejan el dialecto estándar de la lengua española. 
2. Los elementos de cohesión gramatical más empleados son las conjunciones coordinantes, la elipsis y la referencia tanto anafórica como catafórica, las cuales se corresponden con una tipología textual definida por el grado de bilingüismo de los informantes; es decir, la ocurrencia de ciertas formas pronominales como lo y les está mediada por la ausencia de pronombres átonos en los que se distinguen el género y el número como información gramatical explicitada en ciertas marcas reconocibles.

3. La reiteración de nombres constituye un recurso funcional que hace posible el reconocimiento de referentes específicos de manera que las asimetrías de género y número en la estructura textual son soslayables en la interpretación global del texto.

\section{Referencias bibliográficas}

Aguado,J. (2000) Aspecto teórico y metodológico del contacto de lengua. Madrid: Editorial Dossat.

Álvaro, A. (1989). El pronombre. Madrid: Espasa Calpe.

Aikhenvald, A. (2007). Grammars in contact: a cross-linguistic typology. Oxford: Oxford University Press.

Bosque, I. y Demonte, V. (1999). Gramática descriptiva de la lengua española. Madrid: Espasa Calpe.

Bernárdez, E. (1985). Introducción a la lingüistica del texto. Madrid: España.

Bosque, Ignacio y otros. (1998). Lengua Castellana y Literatura I. Madrid: Ediciones Alkal. S. A.

Bosque, Ignacio (2002). Las categorias gramaticales relaciones y diferencias. Madrid: Editorial Síntesis.

Chomsky, N. (1998). Aspectos de la teoría de la sintaxis. Barcelona: Gedisa.

Coral R., K. y Pérez S., J. (2004). Manual de gramática del castellano: variedad estándar y usos regionales. Lima: Proeduca.

Cisneros, M. (2005). Lectura y escritura en la universidad: Una investigación diagnóstica. Pereira: Universidad Tecnológica de Pereira.

Coseriu, E. (2007). Lingüística del texto. Madrid: Arco Libros.

Domínguez, N. (2007). Conectores discursivos en el texto argumentativo breve. Madrid: Arco Libros.

Escobar, M. (1990) Los bilingües y el castellano en el Perú. Lima: IEP.

Escobar, A. (2000). Contacto social y lingüistico. Lima: Fondo Editorial de la PUCP.

Evangelista, D. (2013). Lingüistica del texto: estrategias metodológicas en comprensión lectora. Lima: UNMSM.

Fuentes, C. (1995). Modalidad y conexión en el español en el español coloquial. Madrid: Español Actual. 
Petöfi, J. y García, A. (1978). Lingüística del texto y crítica literaria. Madrid: Gráficos. Halliday y Hasan. (1976). Cohesión y Coherencia. San Paulo: Cortez.

Hernández (1990). Contacto interlingüistico intercultural en mundo bispano. Barcelona: editorial Octaedro.

Ignacio, J., Olarrrea, A., Escobar, A., Catherinee, T. (2009). Introducción a la lingüistica hispánica. Londres: Cambridge University Press.

Koutsoudas (1966). Transformational grammars. Londres: Cambridge University Press.

Lamíquez, V. (1993). Conexión conmutadora entre enunciado. Sevilla: Universidad de Sevilla.

López, Luis Enrique. (1988). Lengua 2. Materiales de apoyo para la formación docente en educación bilingüe e intercultural. Santiago de Chile: UNESCO- OREALC.

Martínez, G. (2012). El pronombre su teoría gramatical y su aprendizaje. Tesis de Maestría, UNMSM, LIMA.

Martínez, M. (2002). Lectura y escritura de los textos: perspectivas teóricas y talleres. Colombia: Cátedra UNESCO.

Moreno, J. (2016) Multilingüismo y lenguas en contacto. Madrid: Editorial Síntesis.

Moreno F., F. (2012). Sociolingüistica cognitiva. Proposiciones, escolios y debates. Madrid, Iberoamericana.

Odlin (1989). Estudio descriptivo del papel de la transferencia lingüistica. Cambridge: Cambridge University Press .

Portolés, J. (2001). Marcadores del discurso. Barcelona: Editorial Ariel.

Rocha M., R. y Conde M., M. (2013). "Relativización de lo fáctico en el discurso: semántica y pragmática de la secuencia como+que en castellano”. En Boletin de la Academia Peruana de la Lengua, vol. 55, n. ${ }^{\circ}$ 55, pp. 189-216.

Seco, M. (1996). Gramática esencial del español. Madrid: Espasa Calpe.

Tusón, A. (2011). Iguales ante la lengua desiguales ente el uso: En el aprendizaje de la comunicación en las aulas. Barcelona: Paidós.

Van Dick, T. (1980). Texto y contexto: Semántica y pragmática discursiva. Madrid: Cátedra.

Weinreich U. (1974). Lenguas en contacto. Descubrimientos y problemas. Venezuela: Ediciones de la Biblioteca Universidad Central de Venezuela.

Zorraquino, M. y Montolío, E. (1998). Los marcadores del discurso. Teoría y análisis. Madrid: Arco. 